\title{
Transcriptomic responses of the basidiomycete yeast Sporobolomyces sp. to the mycotoxin patulin
}

\author{
Giuseppe laniri ${ }^{1,2,4^{*}}$, Alexander Idnurm ${ }^{2,3}$ and Raffaello Castoria ${ }^{1 *}$
}

\begin{abstract}
Background: Patulin is a mycotoxin produced by Penicillium expansum, the causal agent of blue mold of stored pome fruits, and several other species of filamentous fungi. This mycotoxin has genotoxic, teratogenic and immunotoxic effects in mammals, and its presence in pome fruits and derived products represents a serious health hazard. Biocontrol agents in the Pucciniomycotina, such as the yeasts Sporobolomyces sp. strain IAM 13481 and Rhodosporidium kratochvilovae strain LS11, are able to resist patulin and degrade it into the less toxic compounds desoxypatulinic acid and ascladiol.

Results: In this investigation we applied a transcriptomic approach based on RNAseq to annotate the genome of Sporobolomyces sp. IAM 13481 and then study the changes of gene expression in Sporobolomyces sp. exposed to patulin. Patulin treatment leads to ROS production and oxidative stress that result in the activation of stress response mechanisms controlled by transcription factors. Upregulated Sporobolomyces genes were those involved in oxidation-reduction and transport processes, suggesting the activation of defense mechanisms to resist patulin toxicity and expel the mycotoxin out of the cells. Other upregulated genes encoded proteins involved in metabolic processes such as those of the glutathione and thioredoxin systems, which are essential to restore the cellular redox homeostasis. Conversely, patulin treatment decreased the expression of genes involved in the processes of protein synthesis and modification, such as transcription, RNA processing, translation, protein phosphorylation and biosynthesis of amino acids. Also, genes encoding proteins involved in transport of ions, cell division and cell cycle were downregulated. This indicates a reduction of metabolic activity, probably due to the high energy requirement by the cells or metabolic arrest while recovering from the insult caused by patulin toxicity.
\end{abstract}

Conclusions: Complex mechanisms are activated in a biocontrol yeast in response to patulin. The genes identified in this study can pave the way to develop i) a biodetoxification process of patulin in juices and ii) a biosensor for the rapid and cost-effective detection of this mycotoxin.

Keywords: Pucciniomycotina, Transcriptome, Mycotoxins, Biocontrol, Patulin

\section{Background}

Mycotoxins are food contaminants with harmful impact on human and animal health. Their occurrence in commercialized food and feed is a consequence of fungal attacks on crops in the field and/or on stored products. Patulin (PAT) is a mycotoxin produced by species in the

\footnotetext{
*Correspondence: ianirig@umkc.edu; castoria@unimol.it

${ }^{1}$ Dipartimento di Agricoltura, Ambiente e Alimenti, Università degli Studi del Molise, Via F. De Sanctis snc, 86100 Campobasso, Italy

Full list of author information is available at the end of the article
}

fungal genera Aspergillus and Penicillium. P. expansum, the causative agent of the blue mold disease of stored apples, is the main PAT producer and, as a consequence of its attack, PAT is found in different fruits especially pome fruits and derived products. PAT contamination poses a major risk for children, who consume great quantities of fruit juices.

The mechanisms of PAT toxicity and its effects on living cells have been explored for decades $[1,2]$. The main targets of patulin are cellular nucleophiles [3]. In eukaryotic cells, patulin induces oxidative stress by lowering the 
concentration of the antioxidant peptide glutathione, to which it binds due to its electrophilic reactivity, and through generation of reactive oxygen species (ROS) [4, 5]. ROS generation plays a role in the molecular events leading to apoptotic processes particularly by inducing peroxidation of membrane lipids and oxidative DNA damage [6-8].

Genome-wide analysis of the model yeast Saccharomyces cerevisiae on cells exposed to PAT revealed increased levels of transcripts of genes involved in proteasome activity, metabolism of sulfur amino acids, and stress responses, which included transporters involved in detoxification and multidrug resistance, oxidative stress scavengers (thioredoxin and glutathione) and DNA repair genes [9]. Another study in the fission yeast Schizosaccharomyces pombe confirmed the ROS-induced PAT toxicity through glutathione (GSH) depletion, and the activation of antioxidants and redox systems controlled by the transcription factor Pap1 [10], which is the ortholog of Yap1, a key transcription factor that mediates oxidative stress responses in $S$. cerevisiae $[11,12]$ and Cryptococcus neoformans [13]. Moreover, in S. pombe PAT also causes plasma membrane fluidization [14] and changes in chromatin structure [15].

In mammals, the primary target organs of PAT toxicity are the gastrointestinal tract, kidney, liver and the immune system, with acute symptoms of intestinal hemorrhage, ulceration, nausea, edema, dyspnea, convulsion, and agitation. The carcinogenic risk of PAT is classified in group 3 by the International Agency for Research on Cancer [16], since the evidence for its carcinogenicity is considered inadequate in humans and experimental animals. Long-term consequences of exposure to toxic PAT concentrations may include mutagenicity, genotoxicity, embryotoxicity, and exposure to high dosages may include immunosuppression, immunotoxicity and neurotoxicity $[1,2,17]$. The Joint Food and Agriculture Organization/World Health Organization Expert Committee on Food Additives established a maximum tolerable daily intake for PAT of $0.4 \mathrm{mg} / \mathrm{kg}$ body weight/day [18]. Based upon its toxicity profile, legislative regulations in Europe and USA set the highest tolerable levels of PAT in fruit-based products and juices at $50 \mu \mathrm{g} / \mathrm{kg}$, and for baby food at $10 \mu \mathrm{g} / \mathrm{kg}$ (EC Regulation 1881/2006). Despite this restrictive legislation, recent surveys in Europe and USA revealed that PAT contamination is still a common issue [19-21].

In addition to adverse effects on mammals, PAT inhibits microbial growth, having antibacterial, antiviral and antifungal activities, and damages plant cells [2]. As with other secondary metabolites produced by filamentous fungi, the role of PAT is likely to help in competition against other microbes that those fungi encounter in their environment. A gene cluster encoding proteins for PAT biosynthesis has been identified $[2,22]$, and mutation of these genes allowed the study of the role of PAT in the pathogenicity of $P$. expansum, which is still controversial and likely dependent on host factors [23-26].

Postharvest control of $P$. expansum infections is crucial to prevent PAT accumulation in stored fruits. Currently, this is achieved through a combination of cold storage and treatment with chemical fungicides. However, because of ethical, technical and health issues, there is an increasing demand for alternative methods to reduce the use of chemicals; the use of biocontrol agents and/or controlled atmosphere are very promising strategies [21].

Besides reduction of $P$. expansum attack on stored fruits, strategies to detoxify PAT also could provide safer juices for consumption. A number of microbes have been identified that are naturally resistant to PAT, and some have the ability of degrading it. The influence of biocontrol agents (BCAs) that are effective against $P$. expansum on PAT accumulation is an emerging and attractive field of study, and major findings have been recently reviewed [27]. Two ascomycete yeast species, Pichia ohmeri and Candida sake, and a bacterium, Pantoea agglomerans, were able to reduce PAT accumulation; however, the observed reductions were not attributed to direct PAT metabolization but to the protection of fruits from infection by PATproducing $P$. expansum, or by PAT absorption by cell wall and/or into the cells [21, 27]. Conversely, the BCA Rhodosporidium kratochvilovae strain LS11, which is a basidiomycete yeast in subphylum Pucciniomycotina, was able to resist and detoxify PAT in vitro through two independent pathways that led to the formation of breakdown products that are much less toxic than the mycotoxin. The isomers $(E)$ and $(Z)$ of ascladiol, intermediate in PAT biosynthesis, were found as transient products, while desoxypatulinic acid (DPA) was identified as the final product of PAT degradation [28, 29]. Another Pucciniomycotina yeast, Sporobolomyces sp. strain IAM 13481, also converts PAT to DPA and ascladiols, but in this case (E) ascladiol was found as a transient metabolite, while DPA and $(Z)$ ascladiol were the two final breakdown products [30]. More recently, Rhodosporidium paludigenum and other Pucciniomycotina species were found to be able to degrade PAT to DPA and/or ascladiols ([31]; our unpublished data). Therefore, it seems likely that different mechanisms, depending on the species under examination, regulate the expression of the two degradation pathways present in Pucciniomycotina yeasts. The hypothesis of the two distinct pathways is corroborated by the chemical structures of DPA and ascladiols, as they derive from the breakage of bonds that are located in separate ends of the PAT molecule (Fig. 1). Interestingly, while the production of DPA was found only in Pucciniomycotina species, which suggests a peculiar feature of this lineage of basidiomycete fungi, ascladiols were detected after incubation of PAT with 


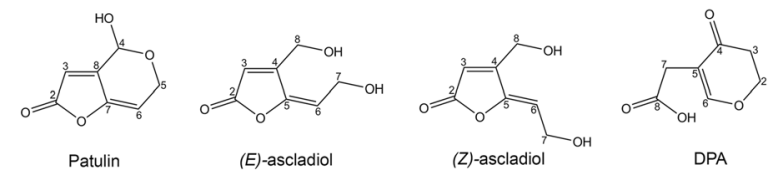

Fig. 1 Chemical structures of patulin and of the three breakdown products (E)-ascladiol, (Z)-ascladiol and desoxypatulinic acid (DPA)

the ascomycete Saccharomyces cerevisiae and with the bacteria Gluconobacter oxydans and Lactobacillus plantarum [32-34], indicating that the ascladiol-forming degradation pathway is likely to be conserved across fungi and bacteria.

We recently explored the molecular mechanisms involved in PAT degradation by Pucciniomycotina yeasts through a random insertional mutagenesis approach: Sporobolomyces sp. IAM 13481 was used as the model organism because of the availability of its genome sequence. However, only a few genes involved in resistance to PAT toxicity were identified [30], suggesting that PAT treatment activates multiple cellular responses that are unlikely to be elucidated in their entirety using a forward genetics strategy.

Therefore, in the present study we analyzed the effects of PAT treatment on Sporobolomyces sp. IAM 13481 cells through a genome-wide approach based on the RNA sequencing (RNAseq). Amongst the fungi there are only two studies that investigated the effect of PAT at the genome-wide level, both on S. cerevisiae, with one analyzing the highly expressed genes, and the second focusing on the differential transcriptional response of a $\operatorname{sod} 1 \Delta$ mutant in comparison with the wild type strain and on the scavenging effect of ascorbic acid $[9,35]$. The present study represents the first application of the high-throughput sequencing technique RNAseq for a non-conventional yeast that is of interest for food safety. The aims were to provide a comprehensive analysis of the genes, the cellular processes and the cellular compartments that play a crucial role in response to PAT treatment, and to identify potential mechanisms and enzymes that are involved in PAT degradation.

\section{Results}

\section{Generation of a reference transcriptome}

The genome sequence of the monokaryon strain IAM 13481 of Sporobolomyces sp. is available on the JGI website at the US Department of Energy (http://genome.jgi-psf.org/ Sporo1/Sporo1.home.html). Its size is $21.2 \mathrm{Mb}$ and includes 76 scaffolds, four of which contained about half of the genome, and 5536 gene models predicted and with putative functions annotated using the JGI annotation pipeline. Although a key taxon used for comparative genomics with the rust fungi [36], the genome is still a draft not available in GenBank, and for an accurate transcriptome analysis a gene annotation upgrade was necessary.
Several approaches were performed for the generation of a reference transcriptome, such as the use of both strand-specific and non-strand specific sequencing, combined or not with the existing gene annotation. According to BLAST similarity analyses of resulting assembled transcripts, the most accurate transcriptome was obtained by merging new genomic traits revealed by strand-specific sequencing to the existing Sporobolomyces sp. annotation.

Strand-specific libraries were prepared from RNA isolated from Sporobolomyces sp. 1) yeast cells grown in the presence and in the absence of $5 \mu \mathrm{g} / \mathrm{ml}$ of PAT (two biological replicates for each of two samples), 2) yeast cells collected from YPD agar medium after 2 days of incubation, 3) ballistospore cells fired on a YPD agar mirror plate, a spore dispersal system that we previously described [37]. The table in Additional file 1 summarizes the samples used for RNA extraction, the type of libraries generated and their use for downstream analysis (i.e. genome annotation and/ or differential gene expression analysis). The transcriptome datasets are available at the NCBI Sequence Read Archive (SRA), under accession number SRP061533.

Gene annotation was performed using the Tuxedo tools. In particular, reads were cleaned and then mapped to the Sporobolomyces genome sequence using Tophat [38]. Approximately 120 million reads ( 20 million per sample) were mapped to single locations in the Sporobolomyces sp. IAM 13481 genome, for a $>95.0 \%$ overall read mapping rate. Tophat outputs were used as inputs for Cufflinks to generate a primary transcriptome for each growth condition; in order to use the existing annotation as a guide for the assembling and for discovering novel transcripts, the RABT (Reference Annotation Based Transcript) assembly was performed. All the Cufflinks outputs were merged in a single final transcriptome through Cuffmerge. The new generated transcriptome consisted of 6595 unique genes and a total of 14462 gene models due to alternative splicing or variable 5' and 3' untranslated regions (UTRs), whose sequences are found in the Additional file 2.

\section{Transcriptome analysis of Sporobolomyces sp. IAM 13481 incubated in the presence of the mycotoxin PAT}

As a first step the effects of PAT on Sporobolomyces sp. IAM 13481 were evaluated by monitoring the yeast growth in the presence of different concentrations of the mycotoxin. As showed in Fig. 2, an increase of PAT concentration progressively affected Sporobolomyces growth, which was characterized by a lag-phase at the higher concentrations of mycotoxin tested (50 and $75 \mu \mathrm{g} / \mathrm{ml}$ ). As we previously reported, the lag-phase is longer when the concentration of PAT increases, and during this stage the mycotoxin is not actively degraded; when the yeast start growing, PAT is degraded and its decrease parallels the onset of the PAT degradation products [30]. Also a lower initial concentration of cells slowed the 


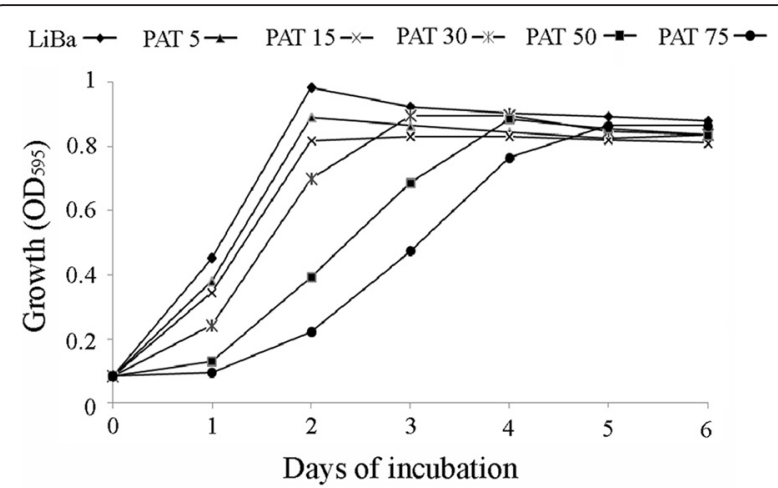

Fig. 2 Growth $\left(\mathrm{OD}_{595}\right)$ of Sporobolomyces sp. after six days of incubation in LiBa medium in the presence of 0, 5, 15, 30, 50 and $75 \mu \mathrm{g} / \mathrm{ml}$ of PAT

growth of Sporobolomyces in the presence of PAT and consequently its degradation. At these tested concentrations, PAT had no morphological effects on Sporobolomyces sp. cells as examined by microscopy.

Initially $50 \mu \mathrm{g} / \mathrm{ml}$ was initially chosen as the optimal PAT concentration since it has an intermediate toxicity on the cells that, however, are able to recover early from the PAT insult. For the first transcriptomic analysis, two independent Sporobolomyces sp. cultures were incubated in the presence and in the absence of $50 \mu \mathrm{g} / \mathrm{ml}$ of PAT. Cells for poly(A) RNA extraction were collected at two different growth levels, within the lag-phase at optical density $595 \mathrm{~nm}\left(\mathrm{OD}_{595}\right) \sim 0.08$, and $\mathrm{OD}_{595} \sim 0.25$ during the phase of active growth (Additional file $3 \mathrm{~A}$ ). It was expected that the transcriptomic analysis performed with the yeast growth in the lag-phase would have revealed mainly the mechanisms behind PAT resistance, while that performed during the log-phase of growth would have elucidated the specific mechanisms of PAT degradation. TLC analysis was performed to monitor the degradation process, since it was pivotal to verify that the expression of the Sporobolomyces sp. genes involved in PAT resistance and degradation was actually occurring. The decrease of the PAT spot progressively paralleled the increase the spots of the breakdown products, and as expected the amount of PAT degraded was higher at $\mathrm{OD}_{595} \sim 0.25$ compared to that at $\mathrm{OD}_{595} \sim 0.08$. Finally, after 4 days of incubation PAT was completely degraded (Additional file 3B).

Non-strand specific sequencing was performed, which we found to be inadequate for an improvement of the existing annotation of Sporobolomyces genome since transcripts were merged into large gene models likely due to the overlapping UTRs of adjacent genes. This is indeed a characteristic of basidiomycete genomes, as revealed by the recent RNAseq-based genome update of the human pathogen Cryptococcus neoformans [39]. Despite this limitation, preliminary bioinformatic analysis using the
Sporobolomyces sp. draft genome revealed that most of the upregulated genes were in common for both samples collected at two different growth stage and included more than 400 genes encoding proteins involved in oxidative and other stress responses, transport and signaling, with no evident insights about the specific mechanisms of PAT degradation (data not shown). Although informative, the large amount of data obtained and the lack of biological replicates did not allow us to focus on genes playing key functions in PAT resistance and/or degradation.

Therefore, several modifications were made to the original experimental design. First, PAT concentration was decreased from $50 \mu \mathrm{g} / \mathrm{ml}$ to $5 \mu \mathrm{g} / \mathrm{ml}$ and cells for RNA extraction were collected after $3 \mathrm{~h}$ of incubation, when Sporobolomyces sp. growth just started increasing and reached an $\mathrm{OD}_{595}$ value of $\sim 0.08$ (Additional file 4A). At this growth rate, PAT was still undegraded and ascladiols and DPA were not detected (Additional file 4B), but the genetic arsenal behind PAT resistance and degradation was active as demonstrated by the reduction of the mycotoxin and the onset of its breakdown products achieved at $\mathrm{OD}_{595} 0.8$ in the same culture used for collecting the cells for analysis (Additional file 4C). The rationale behind lowering PAT concentration was to mitigate the toxic effects of the mycotoxin on the yeast cells and eliminate the lag-phase growth with the aim to detect both resistance and degradation genes involved in the first response to the mycotoxin, hence just at the beginning of the growth even before PAT degradation started. Second, strand-specific sequencing was performed in order to obtain data useful for an improvement of the genome quality, essential for a reliable transcriptomic analysis. Last, two biological replicates for a single time point rather than one replicate at different time points were used, firstly because the use of biological replicates allows for the statistical analysis of the data, and secondly because we did not see significant differences in the differentially expressed genes (DEGs) detected at different time points in our preliminary RNAseq analysis.

Bioinformatic analysis was performed using the Tuxedo tools. The identification of the Sporobolomyces DEGs was performed using Cuffdiff, a statistical tool within the software Cufflinks. The unprocessed Cuffdiff output is available in the Additional file 5. DEGs were considered those with a false discovery rate $(\mathrm{FDR})<0.05$. Using these parameters, 347 genes were found differentially expressed by Sporobolomyces sp. IAM 13481 when incubated in the presence of $5 \mu \mathrm{g} / \mathrm{ml}$ of PAT. Among these, 101 were upregulated and 246 were downregulated (Fig. 3). A heat map of the expression levels of the detected DEGs is shown in the Additional file 6.

All DEGs were subjected to Blast2GO analysis (https:// www.blast2go.com/b2ghome). As expected, species 


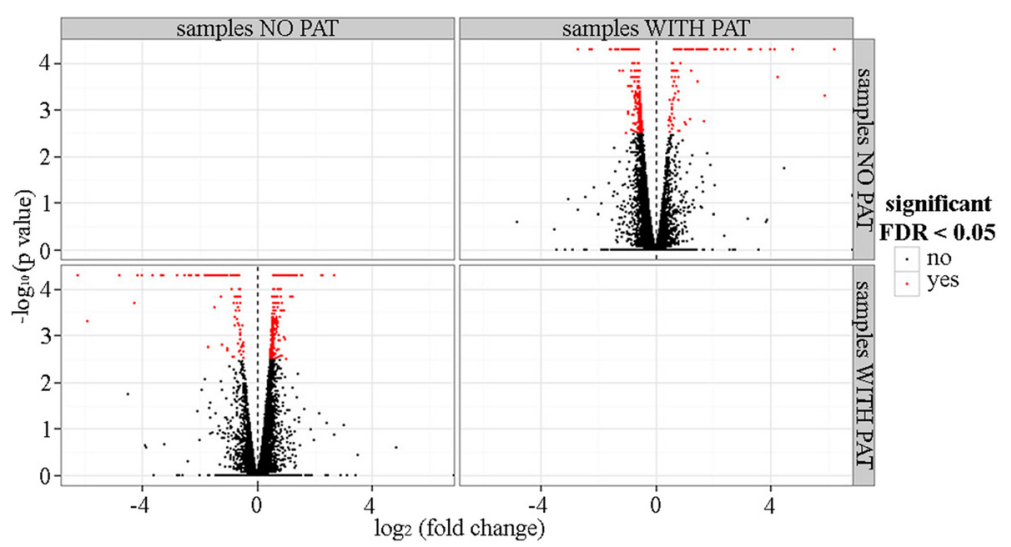

Fig. 3 Volcano plot showing upregulated and downregulated DEGs of Sporobolomyces sp. IAM 13481 grown in the presence of $5 \mu \mathrm{g} / \mathrm{ml}$ of PAT

distribution of all BLAST hits reveals that the majority of them belong to the Basidiomycota phylum, with the most represented belonging to species in the Pucciniomycotina (Rhodosporidium toruloides, Microbotryum violaceum, Mixia osmundae, Melampsora larici-populina, Puccinia graminis and Rhodotorula glutinis), followed by the Agaricomycotina (Rhizoctonia solani, C. neoformans), and the Ustilaginomycotina (Pseudozyma antartica) (Fig. 4). DEGs were functionally annotated using the gene ontology (GO) terms and the biological process category was used for the classification. Blast2GO outcome was improved with manual integration based on the molecular function category and on the role of characterized orthologs. DEGs were used for BLASTx analysis against $S$. cerevisiae to assign gene names and to further integrate gene functions. Combined tables of the RNAseq output, $S$. cerevisiae comparison and blast2GO annotation for upregulated and downregulated genes are found in Additional files 7 and 8, respectively.

Blast2GO analysis of upregulated DEGs assigned GO annotation for 78 genes $(\sim 77 \%)$ that were grouped under the following GO terms: oxidation-reduction process (21 DEGs), metabolic process (19 DEGs), transport (12 DEGs), and transcription factor activity (7 DEGs). Further subclassification of the metabolic process group found 6 DEGs involved in glutathione biosynthesis and turnover and 3 DEGs involved in the thioredoxin system. For the remaining 33 upregulated DEGs either no GO terms were assigned or they belonged to underrepresented GO term groups (Fig. 5). For gene description, the $S$. cerevisiae gene name is used; where not available, the test_id number generated by Cufflinks is used.

The DEGs in the oxidation-reduction process group included oxidases, medium and short chain dehydrogenases, and oxidoreductases that are involved in oxidative stress resistance (OYE2, SRX1, ZTA1, ADH1, GLR1, $C C P 1)$ and/or response to DNA replication stress (ADH6, YML131W, GLR1, SFA1), fatty acid beta oxidation (SPS19) and general stress response (ALD5, ALD4).

The GO group of metabolic process included DEGs encoding proteins involved in the metabolism of different cellular compartments and that play various functions in the cell. The two most expressed DEGs of this group were ENV9 $(\log 2 \mathrm{FC}=4.78)$ and GRE2 $(\log 2 \mathrm{FC}=2.35) . E N V 9$ encodes a NADP-binding protein proposed to be involved

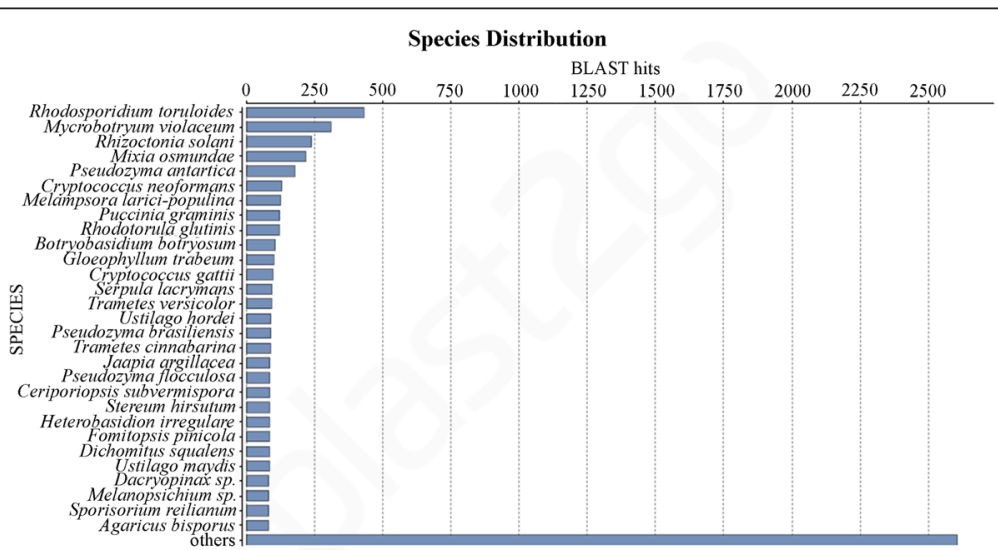

Fig. 4 Species distribution following Blast2GO analysis of DEGs detected in Sporobolomyces sp. grown in the presence of $5 \mu \mathrm{g} / \mathrm{ml}$ of PAT 


$$
\begin{array}{ll}
\square \text { oxidation-reduction process } & \square \text { metabolic process } \\
\square \text { transport } & \square \text { transcription factor activity } \\
\square \text { glutathione system } & \square \text { thioredoxin system }
\end{array}
$$

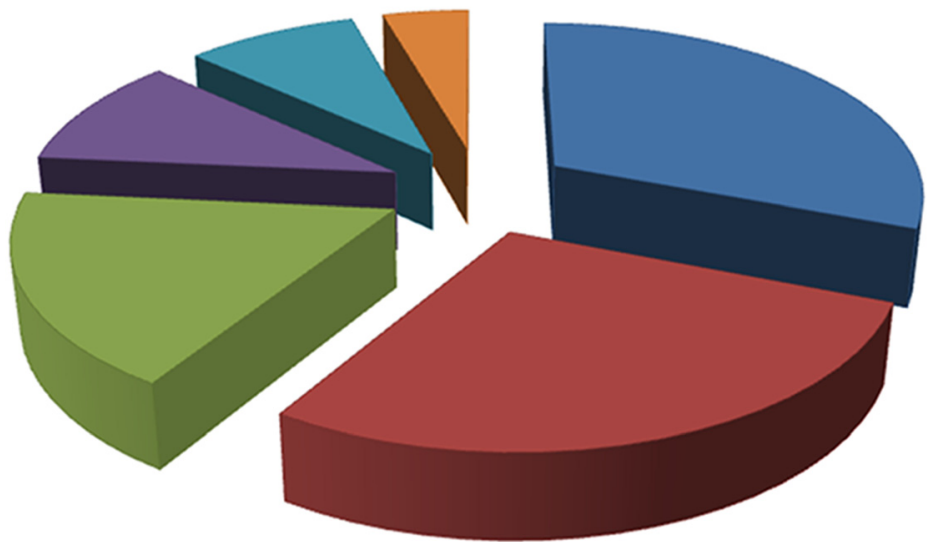

Fig. $5 \mathrm{GO}$ terms representation of upregulated DEGs of Sporobolomyces sp. grown in the presence of $5 \mu \mathrm{g} / \mathrm{ml}$ of PAT in vacuolar functions, and whose $S$. cerevisiae mutant shows defects in carboxypeptidase $\mathrm{Y}$ (CPY) processing and vacuolar morphology [40]. GRE2 encodes a Dlactaldehyde dehydrogenase that is induced by several stresses (osmotic, ionic, oxidative, heat shock and heavy metals), it is regulated by the High Osmolarity Glycerol (HOG) pathway, and is overexpressed in response to DNA replication stress $[41,42]$. Moreover, other DEGs encoded proteins involved in methionine biosynthesis (Met2, Met6 and Met28) and whose induction was also observed by Iwahashi and colleagues in S. cerevisiae [9], confirming that exposure to PAT activates the metabolism of the sulfur amino acid methionine likely because of its known affinity/reactivity with sulfhydryl groups [1].

Based on previous reports indicating an important involvement of glutathione [1,9] and thioredoxin [9] in response to PAT, we specifically searched our transcriptomic data for DEGs whose function is related to these antioxidant compounds. We found 6 DEGs involved in glutathione biosynthesis and turnover and 3 of the thioredoxin system. The most upregulated glutathione gene was the $S$. cerevisiae ortholog URE2 $(\log 2 \mathrm{FC}=4.15)$, which encodes a bifunctional protein that is involved in both nitrogen catabolite repression and oxidative stress response. Ure 2 binds glutathione with high affinity and it has been shown to exhibit glutathione peroxidase activity in vitro; also, its crystal structure shows that it has structural similarity to glutathione $S$-transferase [43-45], which is the GO name assigned following Blast2GO analysis. Other known upregulated DEGs of the glutathione-glutaredoxin system were GSH1, GTT2 and GLR1. Furthermore, our data revealed the upregulated expression of the three genes of the cytoplasmic thioredoxin system, the thioredoxins TRX1 and TRX2, and the thioredoxin reductase TRR1.
The transport category included several genes encoding transmembrane transporters, the most expressed of which was the FLR1-encoding plasma membrane transporter of the major facilitator superfamily (MFS) $(\log 2 \mathrm{FC}=3.22)$. Flr1 is involved in the efflux of fluconazole, diazaborine, benomyl, methotrexate, and other drugs [46], and it was also upregulated in S. cerevisiae exposed to PAT [9]. Other transporter-encoding genes highly upregulated were TPO1 $(\log 2 \mathrm{FC}=2.29)$, known to export polyamines (spermine, spermidine, and putrescine) from the cell during oxidative stress [47], the ATP binding cassette $(\mathrm{ABC})$ transporters PDR15 $(\log 2 \mathrm{FC}=2.61)$ implicated in general stress response and cellular detoxification, and the yeast cadmium factor YCF1 $(\log 2 \mathrm{FC}=2.25)$, a vacuolar glutathione $S$-conjugate transporter required for vacuole fusion and that has a role in detoxifying metals, and transports to the vacuole glutathione disulfide (GSSG) that is not immediately reduced [48, 49].

The last group of upregulated DEGs included those encoding predicted transcription factors classified under GO molecular function terms as specific signal transducer activity and nucleic acid binding. They included two putative transcription factors whose fungal orthologs are non-characterized, and others that include three (CRZ1, YAP1 and SKO1) known to activate transcription of stress response genes.

Besides the DEGs grouped under the most represented GO terms, other upregulated DEGs of interest included those encoding for a stress responsive A/B barrel domain (TCONS_00005994 $\log 2 \mathrm{FC}=3.99)$, for two retrotransposon nucleocapsid proteins (TCONS_00009558, log2FC $=3.64 ;$ TCONS_00000024, $\log 2 \mathrm{FC}=3.34$ ) and for a predicted dienelactone hydrolase (TCONS_00000158, $\log 2 \mathrm{FC}=1.44)$. Last, DEGs for proteins involved in cell 
wall assembly and maintenance (ECM14, EMV1) and DNA repair (WSS1, DDI1) had an expression level lower than 1.

In addition to the DEGs upregulated by PAT, the cuffdiff output was also analyzed to select genes that showed expression values of FPKM (Fragments per Kilobase of Exon per Million Fragments Mapped) only in the presence of PAT. In order to avoid artifacts, genes having a FPKM value greater than 1.5 were selected (Additional file 9). GO analysis revealed that these genes encode proteins that play the same functions as those differentially upregulated, such as sulfur amino acid metabolism (Thr1), oxidation-reduction process (YDL144C, Uga2, YPR127W, Sod2 and Fre5), transport (Flr1, Git1), metabolism (Thr1, Stp14) and DNA repair (Rad53, Rad2). Of note, the overexpression of the superoxide dismutase-encoding gene $S O D 1$ that plays a major role in detoxification of ROS in other species was also anticipated, but BLAST analyses revealed that this gene is absent from the genome of Sporobolomyces sp. IAM 13481.

As regards the downregulated DEGs, Blast2GO assigned GO annotation for 145 genes ( $59 \%)$, with the remaining having no GO sequence description and/or GO classification. Therefore, for a more comprehensive analysis of downregulated Sporobolomyces DEGs in the presence of PAT, manual integration of gene classification and function was performed according to information available for the model ascomycete yeasts S. cerevisiae and S. pombe.

Downregulated Sporobolomyces DEGs were grouped under 7 biological process categories, such as transport (28 DEGs), metabolic and biosynthesis processes (18 and 12 DEGs, respectively) and four other groups including genes that are involved in different steps of the protein synthesis process such as transcription (8 DEGs), RNA processing (20 DEGs), translation (18 DEGs) and protein phosphorylation (7 DEGs). As mentioned above, other genes were grouped according to the model yeast databases as follows: organization of the cytoskeleton (8 DEGs), cell division (4 DEGs), chromatin functions (8 DEGs), cell wall organization and function (4 DEGs) and mitochondrial functions (11 DEGs) (Fig. 6) (Additional file 8).

Downregulated DEGs of the transport group encoded i) proteins that are involved in ions and sugar homeostasis, with calcium being the most represented (YJR124C, Pmr1, Vcx1), and ii) proteins involved in vesicle-mediated transport functions from endoplasmic reticulum (ER) to Golgi, vacuole and other cellular compartments. Within the metabolic and biosynthesis groups, the most represented DEGs were those involved in amino acid biosynthesis and regulation. This result agrees with the downregulation of DEGs involved in different steps of the protein synthesis processes, which also corroborates previous findings in S. cerevisiae [9, 50]. Moreover, many other DEGs encode proteins involved in essential cellular processes such as organization of the cellular cytoskeleton, cell division, chromatin functions, DNA replication, meiosis, and mitosis: this suggests that cells exposed to PAT arrest their growth to have a lower metabolic activity probably because of the high energy requirements of the cells that need to recover from the insult due to the mycotoxin toxicity.

Transcriptomic analyses of Sporobolomyces sp. incubated in the presence of high PAT concentration

The non-strand specific reads of poly(A) RNA extracted from Sporobolomyces sp. incubated in the presence of

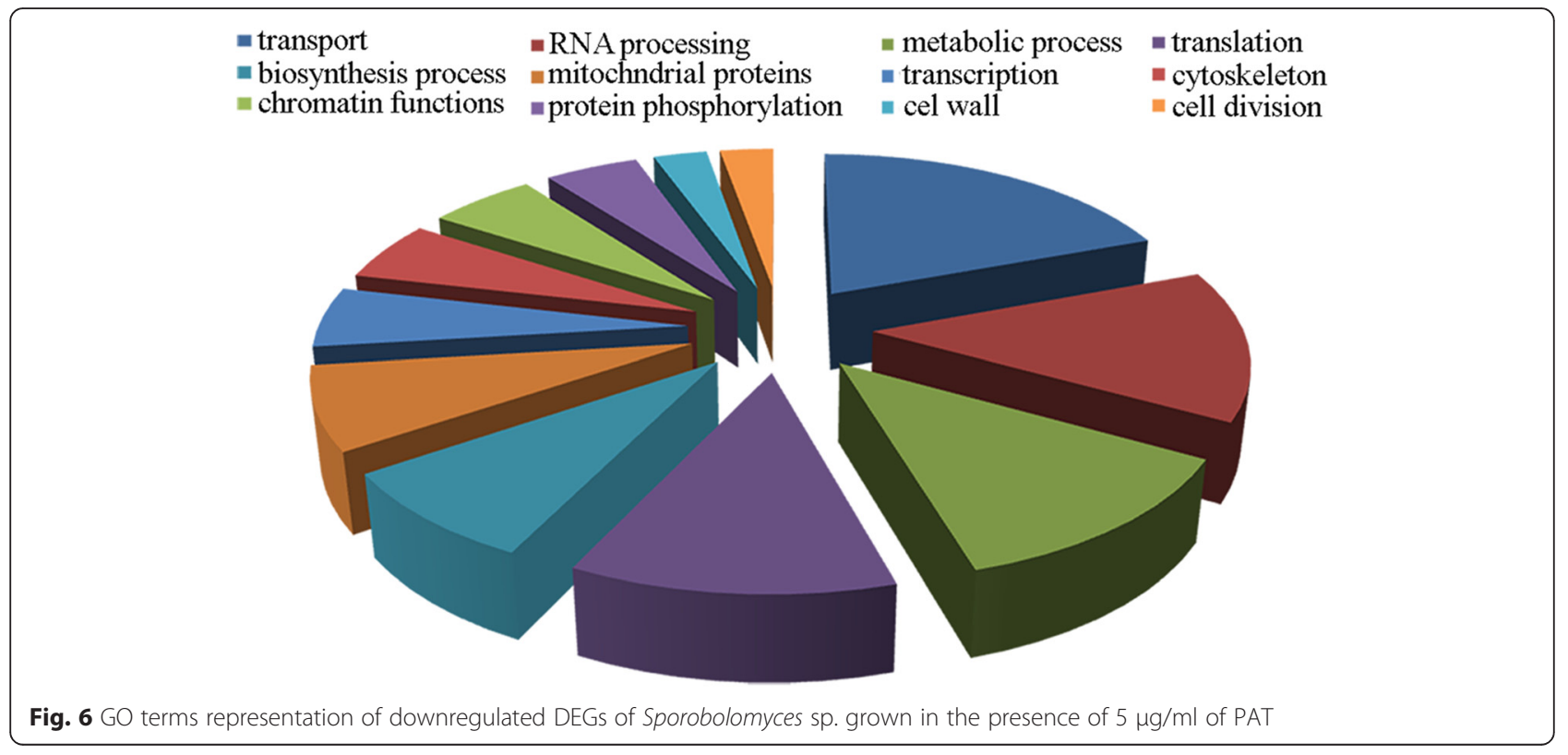


$50 \mu \mathrm{g} / \mathrm{ml}$ of PAT at two different growth levels (Additional file 3) were re-analyzed using the newly generated transcriptome as a reference. Because there was only one biological replicate for each time point, upregulated and downregulated DEGs were considered those having a $\log 2 \mathrm{FC} \geq 2$ and $\leq-2$, respectively. In the samples obtained at $\mathrm{OD}_{595} \sim 0.08$ (indicated as PAT50\#1), 155 upregulated genes were identified, and 31 of them were in common with DEGs found in samples obtained after treatment with the lower PAT concentration (indicated as PAT5); 208 downregulated DEGs with $\log 2 \mathrm{FC} \leq-2$ were found, and 19 were in common with PAT5 (Additional file 10). Furthermore, at growth level of $\mathrm{OD}_{595} \sim 0.25$ (indicated as PAT50\#2) we found 204 upregulated and 188 downregulated DEGs, of which 37 and 10 were in common with PAT5, respectively (Additional file 11). Last, there was a higher similarity between the two samples exposed to $50 \mu \mathrm{g} / \mathrm{ml} \mathrm{PAT}$, with 118 upregulated and 63 downregulated DEGs in common. The transcriptional differences in cultures exposed to either 5 or $50 \mu \mathrm{g} / \mathrm{ml}$ of PAT may be due to the different concentrations used and to the criteria used to select DEGs, since the FDR applied to analyze biological replicates can also select genes with $\log 2 \mathrm{FC}$ lower than 2 and -2 .

Amongst the three different transcriptomic datasets of this study (PAT5, PAT50\#1 and PAT50\#2), some of the most upregulated DEGs in all the samples were selected and their expression levels compared at different PAT concentrations and at two different growth stages (Fig. 7). As expected, at a similar growth level (i.e. $\left.\mathrm{OD}_{595} \sim 0.08\right)$ an increase of PAT concentration from 5 to $50 \mu \mathrm{g} / \mathrm{ml}$ led to a higher expression of all the DEGs selected, with the exception of YML131W and URE2. Also, for the majority of the selected genes there was a minimum of a one-unit $\log 2 \mathrm{FC}$ increment of expression at $50 \mu \mathrm{g} / \mathrm{ml}$, indicating that the abundance of transcripts for proteins such as Oye2, Adh1, Flr1, and others, relate to PAT toxicity and thus specifically required to defeat the cellular insult caused by the mycotoxin. Conversely, the expression of other genes (ADH6, YML131W, ENV9, URE2, TPO1, YCF1 and PDR15) did not considerably differ at the two tested PAT concentrations, suggesting that the encoded proteins might be involved in general response to a toxic molecule (Fig. 7a). Furthermore, with the exception of PDR15, there was a higher expression of all the genes selected during the growth of Sporobolomyces in the presence of $50 \mu \mathrm{g} / \mathrm{ml}$ of PAT (Fig. 7b), suggesting that the mechanisms to overcome PAT toxicity might be active and increase during the degradation process while PAT is still present in the medium.

Real time reverse transcriptase PCR was used to validate the expression levels of a subset of common genes identified in the three transcriptomic datasets. The relative expression levels of OYE2, ENV9, URE2, FLR1, TCONS_00006843 and TCONS_00005994 by PAT treatment were tested. All six genes had high transcript levels in response to different patulin concentrations, confirming the regulation of these genes defined by the RNAseq data (data not shown).

\section{Discussion}

By combining the transcriptomic data obtained in the present study with the previous experiments primarily in $S$. cerevisiae, we provide an overview of the global effects of PAT on Sporobolomyces sp. and other eukaryotes (Fig. 8). The genera Sporobolomyces and Saccharomyces diverged an estimated 800-1600 million years ago, with those estimates based on different molecular clock calibrations [51]. Hence, observing a common set of differentially-regulated genes that are shared over such long time frames could indicate key components regulated in response to this mycotoxin.

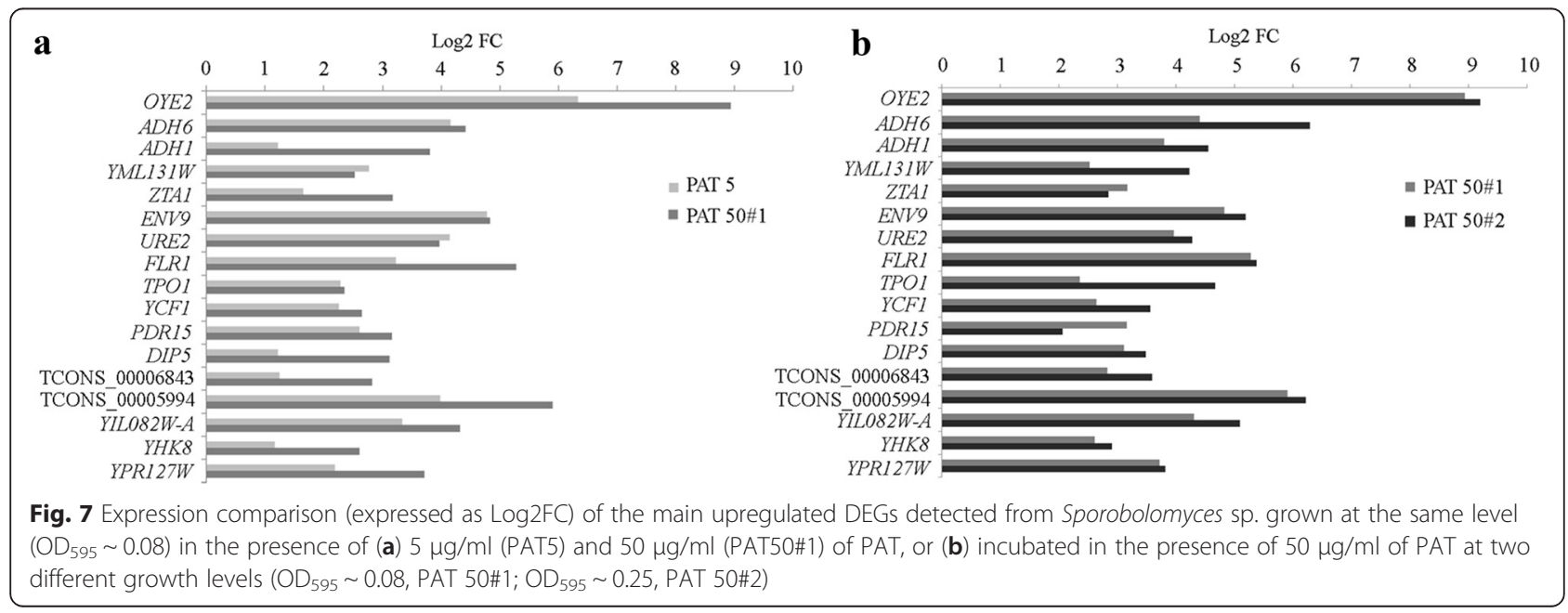




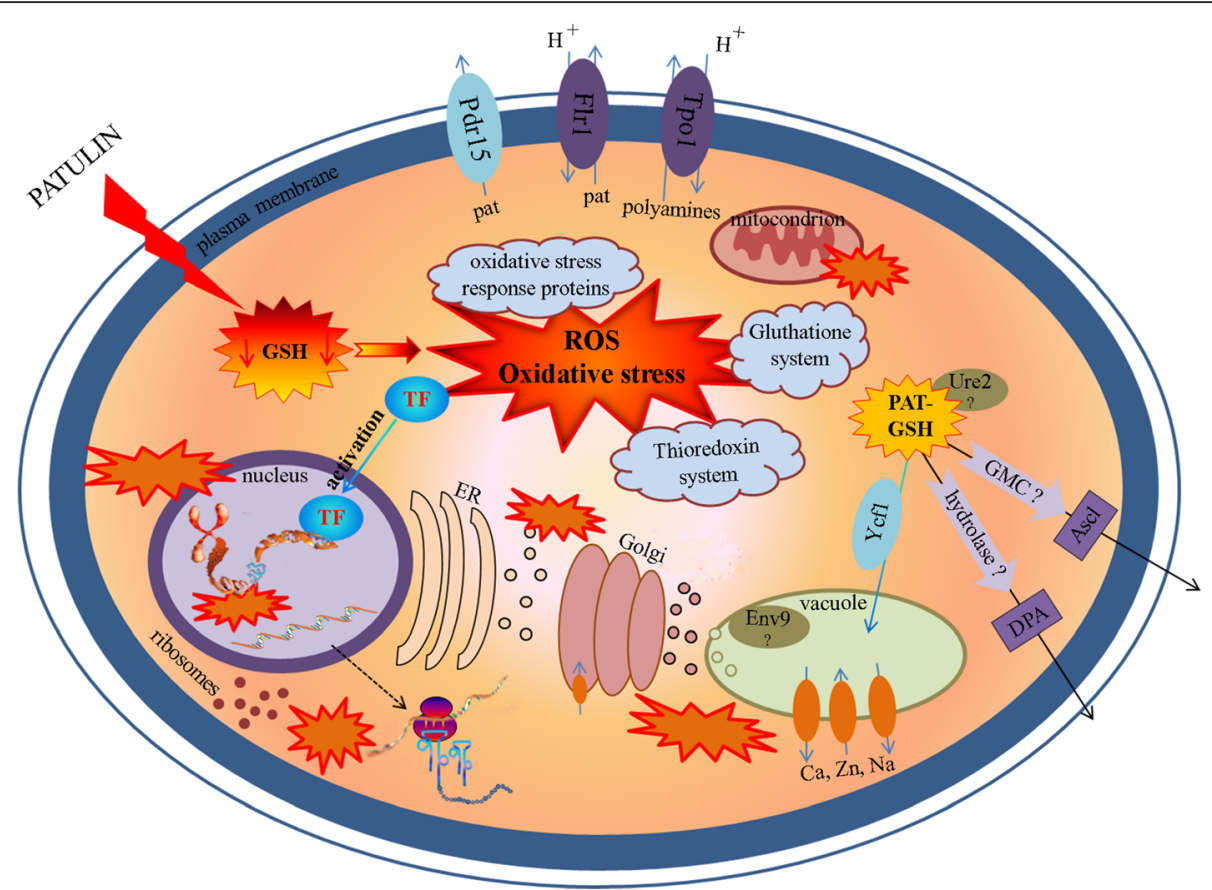

Fig. 8 Model for Sporobolomyces sp. responses to the mycotoxin PAT. The model is based on information found in the present study and in the existing literature (see Discussion for details). The explosion shapes indicate oxidative damages. GSH is gluthatione; PAT-GSH is glutathione adduct with PAT mediated by Ure2; TF is transcription factor; ER is endoplasmic reticulum. The question marks indicate an unknown function/process

\section{Effects of PAT on cells}

At a cellular level, PAT has a high electrophilic reactivity with sulfhydryl group-containing compounds [4, 52]. The mycotoxin interacts with the cell wall and targets free thiols of the outer surface of the plasma membrane [14, 53] thus compromising its permeability and integrity. This, in conjunction with the low molecular weight of PAT, allows the mycotoxin to enter the cell, most likely through passive diffusion without the involvement of transporters or energy-dependent pumps. A significant role in plasma membrane destabilization is likely due also to lipid peroxidation caused by the oxidative burst described below.

Once in the cell, PAT causes GSH depletion through reaction with its sulfhydryl groups; this results in the alteration of the cellular redox homeostasis $[5,6]$. We suggest that this is the key event for PAT cytotoxicity as it results in an increased generation of ROS and a subsequent oxidative burst that induces early transmission of stress signals and is responsible for the damage to cellular components. As highlighted in the following description, this hypothesis is based on the transcriptional response of $S$. cerevisiae to PAT $[9,35]$ as well as with ROS-mediated stress response studies in $S$. cerevisiae and $C$. neoformans $[11,12,54]$.

\section{Transmission of stress signals}

Based on a number of lines of evidence, hydrogen peroxide $\left(\mathrm{H}_{2} \mathrm{O}_{2}\right)$ is a major $\mathrm{ROS}$ involved in signaling responses and is produced by NAPDH oxidases in conjunction with superoxide dismutase $[11,12,54]$. We suggest that the Sporobolomyces sp. adaptive response to oxidative stress generated by PAT is regulated by the transcription factors identified in our analysis, which in conjunction activate the expression of stress-response proteins, and antioxidant and detoxification systems. Of note, it is likely that an important role is played by Yap1, since this bZIP transcription factor is a key component in $\mathrm{H}_{2} \mathrm{O}_{2}$-mediated signaling transduction in $\mathrm{S}$. cerevisiae $[11,12]$ where it is overexpressed also following PAT treatment $[9,35]$; other S. cerevisiae transcription factors upregulated following PAT and ROS exposure are Skn7, Msn2 and Msn4. However, they were not identified in our study, suggesting that the response of Sporobolomyces and S. cerevisiae to ROS involves different transcription factors, with the exception of Yap1.

\section{Activation of stress responsive proteins}

Genes of Sporobolomyces sp. encoding cytoplasmic (Oye2, Adh6, Gre2, Yml131w, Sps19, Zta1, Adh1, etc.) and mitochondrial proteins (Oye2, Sod2, Ald4, Ald5, Sfa1, Erv1, etc.) that are upregulated following oxidative stress are designed with the GO molecular function term "oxidoreductase activity". Interestingly, the majority of these stress responsive genes were overexpressed in $S$. cerevisiae also in response to DNA damaging-agents [42], implicating oxidative damage to 
DNA caused by PAT as previously reported in other studies $[6,55,56]$.

\section{Activation of antioxidant systems}

In concordance with the findings of Iwahashi et al. in $S$. cerevisiae [9], our analysis revealed that the most important increase in transcript levels was in Sporobolomyces genes associated with the antioxidant molecules glutathione and thioredoxin. However, as regard the glutathione cycle, we only found upregulation of URE2, GSH1 and GLR1, while in S. cerevisiae Iwahashi and colleagues found also GRX2 and PRX1 that encode respectively the cytoplasmic glutaredoxin and the mitochondrial thioredoxin. Also, we did not detect the genes encoding for the antioxidant proteins Tsa1, Tsa2, Ahp1, Ahp2 (peroxiredoxins) and Hyr1 (thiol peroxidase). Another important scavenger system activated by Sporobolomyces in response to PAT is the thioredoxin one: on the basis of our transcriptomic data, this system involves mainly the three cytoplasmic proteins Trr1, Trx1 and Trx2. In S. cerevisiae the thioredoxin system is preceded by the peroxiredoxin cycle [11] whose components (Tsa1, Tsa2, Ahp1 and Ahp2) were overexpressed also in Sporobolomyces sp. exposed to PAT, although not statistically significant according to Cuffdiff. These antioxidant systems are well conserved amongst fungi and their function in Sporobolomyces sp. is likely the same as in S. cerevisiae [11] and in the basidiomycete yeast C. neoformans in which they have been characterized [57].

\section{Export and detoxification proteins}

Another mechanism mediated by the transcription factors in response to the oxidative stress caused by PAT is the activation of genes encoding transmembrane transporters involved in export of metabolites from the cell. The main transporters identified were the MFS member Flr1 and the $A B C$ transporter Pdr15. We suggest that these proteins are involved in PAT efflux in a similar way as occurs in the multidrug resistance in fungi and bacteria. Also, the MFS transporter Tpo1 likely exports polyamines during PAT-induced oxidative stress, as suggested for S. cerevisiae [47].

\section{Mechanisms of PAT degradation}

PAT is degraded in Sporobolomyces sp. through two independent pathways that lead to the formation of DPA and ascladiols [30]. The same PAT breakdown products have been identified in other Pucciniomycotina yeasts such as $R$. kratochvilovae [28, 29], $R$. paludigenum [31] and Rhodotorula mucilaginosa (our unpublished data). Following our transcriptomic analysis we suggest that PAT degradation occurs through different ways and an essential step is the formation of enzymatic adducts of PAT with GSH, as documented by Fliege and Metzler [4]. We propose that the degradation occurs at least in part in the vacuole, likely mediated by the $\mathrm{ABC}$ transporter Ycf1 that binds PAT-GSH adducts and actively transports them to the vacuole for non-specific degradation; other vacuolar proteins, such as Env9, may also be involved. This GSH mechanism controls resistance of $S$. cerevisiae to the oxidative stress-inducing heavy metals cadmium, nickel, arsenic and mercury [58-60]. Of note, the enzymatic adducts are likely formed by proteins with glutathione $S$-transferase activity [4] such as Ure2, which is one of the highly expressed DEGs in our analysis. Whether or not the formation of the PAT breakdown products DPA and ascladiol occurs in the vacuole, other organelles, or in the cytosol needs to be further investigated.

DPA is the most important metabolite of PAT degradation because i) it is characterized by a lower cytotoxicity than PAT, most likely because of its very low reactivity with thiol groups [29], ii) it is the most abundant breakdown metabolite, and iii) it is produced by all the Pucciniomycotina found as able to degrade PAT. DPA is most likely formed through the hydrolysis of the $\alpha, \beta$-unsaturated $\gamma$-lactone ring of PAT (Rosa Durán-Patrón, personal communication), a mechanism that is similar to the biodetoxification of zearalenone by the zearalenone hydrolase/lactonase Zdh101 produced by the BCA Clonostachys rosea [61]. Orthologs of Zdh101 were not found amongst the DEGs identified in this study as well as in Sporobolomyces and other sequenced Pucciniomycotina genomes. Therefore, we searched for genes encoding proteins with predicted hydrolase activity on lactone rings and found in our DEGs a predicted dienelactone hydrolase (TCONS_00000158). We previously generated a targeted mutant for this gene as well as for another gene encoding a dienelactone hydrolase, the latter not detected as being differentially expressed in our analysis. Surprisingly, both mutants had the same kinetics of PAT degradation as the Sporobolomyces wild type strain (unpublished data), indicating that these genes are not involved in PAT degradation. Perhaps suitable candidates for DPA generation could be the newly identified gene (TCONS_00005994) that encodes a protein containing a stress responsive $\mathrm{A} / \mathrm{B}$ barrel domain of unknown function, another gene (TCONS_00013529) that encodes a protein designed as a catalytic $\mathrm{LigB}$ subunit of aromatic ring-opening dioxygenase (TCONS_00013529), or one of the upregulated short or medium chain dehydrogenases that are potentially able to degrade xenobiotic compounds.

As regards ascladiol, from a chemical viewpoint it results from the hemiacetal opening of PAT and reduction of the derived aldehyde. (E)-ascladiol is oxidized to PAT in one step enzymatic reaction in PAT biosynthesis [62]; thus, it is reasonable that the reverse enzymatic reaction leads to the formation of $(E)$-ascladiol from PAT. It has 
been recently suggested that the $P$. expansum gene PatE encoding a Glucose-methanol-choline (GMC) oxidoreductase is responsible for the last step in PAT biosynthesis [22], even though this hypothesis has not been experimentally established yet. Strikingly, BLASTp analysis revealed that $P$. expansum PatE corresponds to the Sporobolomyces GMC oxidoreductase that was found to be upregulated in the present study (TCONS_00004874), and potentially this enzyme may be responsible for the conversion of PAT into ascladiol. Future studies using reverse genetics will allow the elucidation of the role of the upregulated Sporobolomyces sp. DEGs in PAT resistance and degradation.

\section{Damage to cellular components}

Besides the role of ROS as signaling molecules, they are mainly responsible for PAT cytotoxicity. In fact, despite the rapid upregulation and high efficiency of antioxidant defenses, cells can still sustain severe organelle damage and inhibition of biological processes essential for cellular life. The cytotoxic effects of PAT have been studied for over 30 years, as reviewed in 2005 and 2010 [1, 2], and they recall the cellular damage observed in $S$. cerevisiae exposed to ROS [12]. Lipid peroxidation causes perturbing effects on the plasma and other organelle membranes with loss of intracellular components and altered homeostasis. Furthermore, oxidative DNA and RNA damage compromises nucleic acids integrity and functionality hence interfering with their synthesis and replication; the actin cytoskeleton is another target of PAT as well as of ROS, and the physiological consequences of its oxidation include accelerated aging and apoptotic cell death [63].

\section{Conclusions}

This is the first study where a next generation sequence (NGS) technique has been applied to depict the complex molecular effects of the mycotoxin PAT on a nonconventional basidiomycete yeast that is able to degrade it and has biocontrol activity against the PAT-producing fungus $P$. expansum. Our study when compared with previous findings from $S$. cerevisiae about PAT cytotoxicity provides compelling evidence for common cellular targets and responses, yet it also discloses new aspects such as novel mechanisms of stress response activation, which may represent a specialized feature of the Pucciniomycotina fungi. Two attractive long term goals are 1) the development of a biosensor, based on upregulated Sporobolomyces and S. cerevisiae genes in response to or even that bind the mycotoxin, for user-friendly and economical procedures for PAT detection and quantification in products ready for commercialization; and 2) the functional characterization of genes involved in conversion of PAT to DPA and/or ascladiol that will create the premises for production of enzymes responsible for PAT detoxification in heterologous cell factories in which the identified genes are transformed. These enzymes could be the base for detoxification processes of products and juices derived from pome fruits.

\section{Methods}

\section{Strain used and cultivation}

Sporobolomyces sp. strain IAM 13481 was used in this study. The strain was routinely cultivated on yeast peptone dextrose medium (YPD: Yeast extract $10 \mathrm{~g} / \mathrm{l}$, Peptone 20 g/l, D-glucose 20 g/l, Agar 20 g/l). Sporobolomyces sp. was incubated at concentration of $1 \times 10^{7} \mathrm{CFU} / \mathrm{ml}$ in Lilly Barnett medium (LiBa, $10.0 \mathrm{~g}$ D-glucose, $2.0 \mathrm{~g} \mathrm{~L}$-asparagine, $1.0 \mathrm{~g} \mathrm{KH}_{2} \mathrm{PO}_{4}, 0.5 \mathrm{~g} \mathrm{MgSO}_{4} \cdot 7 \mathrm{H}_{2} \mathrm{O}, 0.01 \mathrm{mg} \mathrm{FeSO} \mathrm{H}_{4}$. $7 \mathrm{H}_{2} \mathrm{O}, 8.7 \mathrm{mg} \mathrm{ZnSO}_{4} \cdot 7 \mathrm{H}_{2} \mathrm{O}, 3.0 \mathrm{mg} \mathrm{MnSO}_{4} \cdot \mathrm{H}_{2} \mathrm{O}$, $0.1 \mathrm{mg}$ Biotin, and $0.1 \mathrm{mg}$ Thiamine, per Liter) [64] supplemented with $5,15,30,50$ and $75 \mu \mathrm{g} / \mathrm{ml}$ of PAT (A.G. Scientific, Inc.; San Diego, CA, USA), and the growth monitored on a daily basis by reading the $\mathrm{OD}_{595}$ in a microplate reader. Transcriptomic analysis was performed for Sporobolomyces sp. incubated in the presence of $5 \mu \mathrm{g} / \mathrm{ml}$ and $50 \mu \mathrm{g} / \mathrm{ml}$ of PAT. With $5 \mu \mathrm{g} / \mathrm{ml}$ of PAT, two biological replicates were used; Sporobolomyces sp. cells were added to $200 \mathrm{ml}$ of LiBa medium and incubated on an orbital shaker at $24{ }^{\circ} \mathrm{C}$ until the growth reached a $\mathrm{OD}_{595}$ of $\sim 0.08$ $(\sim 3 \mathrm{~h})$. The untreated cultures were Sporobolomyces sp. incubated in LiBa without PAT at the same growth level. The cultures were centrifuged to collect cells for RNA extraction, and an aliquot of each supernatant obtained was analyzed through HPLC as previously described [30] to monitor the degradation of PAT at the time of extraction. When $50 \mu \mathrm{g} / \mathrm{ml}$ of PAT was used, two independent Sporobolomyces sp. cultures of $50 \mathrm{ml}$ were incubated on an orbital shaker at $24{ }^{\circ} \mathrm{C}$ and cells for RNA extraction were collected by centrifugation at $\mathrm{OD}_{595}$ of $\sim 0.08$ from one culture, and at $\mathrm{OD}_{595}$ of $\sim 0.25$ from the other; untreated conditions were LiBa medium without PAT inoculated with Sporobolomyces sp. IAM 13481 reaching the same growth levels. In this case the supernatants obtained were used to assess through TLC analysis [30] the degradation of PAT at the times of RNA extraction. Moreover, both at PAT 5 and $50 \mu \mathrm{g} / \mathrm{ml}$, aliquots of the growth cultures from which cells were collected for RNA extraction were re-incubated and used to assess Sporobolomyces growth and PAT degradation for several days, since it was pivotal to verify that the mechanisms behind PAT resistance and degradation were active.

Besides the incubation in the presence of PAT, Sporobolomyces sp. RNA was extracted also from cells collected on YPD agar after two days of growth, and from fired ballistospores collected from a mirror YPD plate [37]; in the present study these data were only used for the generation of the Sporobolomyces sp. reference transcriptome 
(Additional file 1). Collected yeast cells were frozen, lyophilized and stored at $-80^{\circ} \mathrm{C}$ until RNA extraction.

\section{RNA extraction and Illumina sequencing}

Total RNA was extracted from Sporobolomyces sp. cells with the Trizol reagent according to the manufacturer's instruction (Invitrogen, Grand Island, NY). Quality and concentration of total RNA was checked by gel electrophoresis and a spectrophotometer, respectively. Libraries construction and Illumina sequencing were performed at the DNA Core Facility of the University of MissouriColumbia. For RNA samples obtained from Sporobolomyces sp. cells incubated in the presence of $50 \mu \mathrm{g} / \mathrm{ml}$ of PAT and respective controls, TruSeq non-strand specific libraries were prepared. For RNA samples extracted from Sporobolomyces sp. cells incubated in the presence of $5 \mu \mathrm{g} / \mathrm{ml}$ of PAT and from a mirror plate, including their respective controls, TruSeq strand-specific libraries were prepared since this method allows a more accurate generation of a reference transcriptome (Additional file 1). In both cases, $100 \mathrm{bp}$ single end reads were sequenced using an Illumina HiSeq2000 instrument.

\section{Bioinformatic analyses of the expression of the RNAseq libraries}

Bioinformatic analyses were performed using the Tuxedo tools [38]. First, the existing Sporobolomyces sp. genome annotation was examined using the RNAseq data presented in this study. To this aim, a total of six strandspecific libraries generated as reported above were used. The Sporobolomyces sp. genome sequence (.fasta format) and annotation (.gtf format) were downloaded from the US Department of Energy's Joint Genome Institute website (http://genome.jgi-psf.org/Sporo1/Sporo1.home.html). Cleaned reads generated from all six conditions were individually mapped to the Sporobolomyces sp. genome sequence using Tophat. Generated bam files were used to run Cufflinks with the RABT (Reference Annotation Based Transcript) assembly, an option that it is able to integrate novel transcripts in the existing genome annotation. Cuffmerge was then used to merge all the .gtf files generated by Cufflinks into the reference transcriptome used in downstream differential analysis. Novel Sporobolomyces sp. genes were those that did not find a corresponding match in the JGI Sporobolomyces sp. genome annotation. Gene names were assigned according to the Saccharomyces genome database (SGD) following BLASTx analysis; matches with $E$-value higher than $1 \mathrm{E}-3$ were not considered because they indicated different orthologs having only low similarity. Cuffdiff, the statistical software for gene expression analysis, was run to compare the Tophat outputs deriving from samples of Sporobolomyces sp. incubated with and without $5 \mu \mathrm{g} / \mathrm{ml}$ of PAT (Additional file 1), and with the newly generated transcriptome as reference.
Sporobolomyces sp. DEGs were considered those with a FDR $<0.05$. Graphical representations were performed using CummeRbund within the R package. Functional annotation of Sporobolomyces sp. DEGs was performed using the Blast2GO pipeline, which includes the BLASTx against the NCBI non-redundant protein database, gene ontology (GO) annotation and InterProScan [65].

Non-strand sequences generated from samples of Sporobolomyces sp. incubated with or without $50 \mu \mathrm{g} / \mathrm{ml}$ of PAT at two time points were analyzed using TophatCufflinks as described above; the newly generated strand-specific based reference transcriptome was used. Because samples were as single biological replicates, DEGs were selected based on the Log2FC expression values, with those $\geq 2$ being upregulated and those $\leq-2$ downregulated. DEGs selected were compared with those obtained for Sporobolomyces sp. incubated with $5 \mu \mathrm{g} / \mathrm{ml}$ of PAT, as indicative of the reliability of our analysis since these datasets originated from three different and independent conditions. Furthermore, in order to evaluate the genetic effects of the PAT concentration and the incubation time, the Log2FC expression values of the main upregulated DEGs of these three datasets were compared.

\section{Availability of supporting data}

All the supporting data are included as Additional file.

\section{Additional files}

Additional file 1: Table reporting growth conditions used to collect Sporobolomyces samples for RNA extraction, the type of cDNA libraries generated, and their use for downstream analysis. (DOCX 79 kb)

Additional file 2: All new assembled Sporobolomyces sp. isoforms used for BLAST analyses. (TXT $34275 \mathrm{~kb}$ )

Additional file 3: (A) Growth of Sporobolomyces sp. in LiBa medium in the presence and absence of $50 \mu \mathrm{g} / \mathrm{ml}$ of PAT. The arrows indicate when Sporobolomyces sp. cells were collected for RNA extraction. (B) TLC analysis of the growth medium from which Sporobolomyces sp. cells were collected for RNA extraction. The lanes with asterisks correspond to the time when Sporobolomyces sp. cells were collected (i.e. grey arrows). PAT = patulin; DPA = desoxypatulinic acid; $A S C L=$ ascladiol. TLC analysis was performed until no more PAT was detected. (TIF $749 \mathrm{~kb}$ )

Additional file 4: (A) Growth of Sporobolomyces sp. in LiBa medium in the presence and absence of $5 \mu \mathrm{g} / \mathrm{ml}$ of PAT, with the first five hours showed in detail in the small box. The arrows indicate when Sporobolomyces sp. cells were collected for RNA extraction. (B) HPLC analysis showing an overlay between the growth medium containing Sporobolomyces cells with PAT $5 \mu \mathrm{g} / \mathrm{ml}$ at the time of RNA extraction, and a cell-free LiBa plus PAT $5 \mu \mathrm{g} / \mathrm{ml}$; note that the PAT peaks have the same area, indicating that PAT degradation had not started yet. (C) HPLC chromatograms of the growth medium from which Sporobolomyces cells were collected for RNA extraction after $48 \mathrm{~h}$ of incubation $\left(\mathrm{OD}_{595} \sim 0.8\right)$. As already known, only (Z)-ascladiol and DPA were clearly detected as the final products of PAT degradation by Sporobolomyces. (TIF 124 kb)

Additional file 5: Unprocessed Cuffdiff output of the RNAseq experiments performed for Sporobolomyces grown in the presence of $5 \mu \mathrm{g} / \mathrm{ml}$ of PAT. Where no Sporobolomyces gene models are indicated 
based on the previous JGl annotation (column C), it indicates a novel transcript identified following the transcriptomic analysis presented in this study. (XLSX $1622 \mathrm{~kb}$ )

Additional file 6: Heat map showing upregulated and downregulated DEGs of Sporobolomyces sp. grown in the presence of $5 \mu \mathrm{g} / \mathrm{ml}$ of PAT. (TIF $22235 \mathrm{~kb}$ )

Additional file 7: Combined table of cuffdiff, Blast2GO and BLASTx outputs for upregulated Sporobolomyces sp. DEGs (FDR < 0.05) detected in the presence of $5 \mu \mathrm{g} / \mathrm{ml}$ of PAT. DEGs are grouped based on GO term classification, and within the groups sorted for log2 FC values (from the highest to the lowest). BLASTx results with existing Sporobolomyces sp. genome annotation were useful to identify new genes detected in the present study, while BLASTx against SGD was necessary to identify Sporobolomyces sp. orthologs in S. cerevisiae; low homology (i.e. E-values positive or higher than $1 \mathrm{E}-3$ ) was reported as NA indicating that no S. cerevisiae orthologs of Sporobolomyces sp. DEGs were found. (XLSX $27 \mathrm{~kb})$

Additional file 8: Combined table of cuffdiff, Blast2GO and BLASTx outputs for downregulated Sporobolomyces sp. DEGs $(F D R<0.05)$ detected in the presence of $5 \mu \mathrm{g} / \mathrm{ml}$ of PAT. DEGs are grouped based on GO term classification and within the groups sorted for log2 FC values (from the lowest to the highest). BLASTx results with existing Sporobolomyces sp. genome annotation were useful to identify new genes detected in the present study, while BLASTx against SGD was necessary to identify Sporobolomyces sp. orthologs in S. cerevisiae and accordingly assign gene names; low homology (i.e. E-values positive or higher than $1 \mathrm{E}-3$ ) was reported as NA indicating that no S. cerevisiae orthologs of Sporobolomyces sp. DEGs were found. (XLSX $54 \mathrm{~kb}$ )

Additional file 9: Combined table of cuffdiff, Blast2GO and BLASTX outputs for Sporobolomyces sp. genes detected only in the presence of $5 \mu \mathrm{g} / \mathrm{ml}$ of PAT. DEGs have been sorted for FPKM expression values (from the highest to the lowest), and those with FPKM lower than 1.5 were discarded. BLASTx results with existing Sporobolomyces sp. genome annotation were useful to identify new genes detected in the present study, while BLASTX against SGD was necessary to identify Sporobolomyces sp. orthologs in yeast and to assign gene names accordingly; low homology (i.e. E-values positive or higher than 1E-3) was reported as NA, indicating that no S. cerevisiae orthologs of Sporobolomyces sp. DEGs were found. (XLSX $13 \mathrm{~kb}$ )

Additional file 10: Combined table of cuffdiff and BLASTX outputs for upregulated (Log2FC $\geq 2$ ) and downregulated (Log2FC $\leq-2)$ DEGs detected for Sporobolomyces sp. grown in the presence of $50 \mu \mathrm{g} / \mathrm{ml}$ of PAT at $\mathrm{OD}_{595}$ of $\sim 0.08$. BLASTx against existing Sporobolomyces $\mathrm{sp}$. genome annotation and SGD is also shown. DEGs have been sorted from the highest Log2FC value to the smallest. In bold are indicated DEGs found also for Sporobolomyces sp. incubated in the presence of $5 \mu \mathrm{g} / \mathrm{ml}$ of PAT reported in additional files 7 and 9. (XLSX $52 \mathrm{~kb}$ )

Additional file 11: Combined table of cuffdiff and BLASTX outputs for upregulated (Log2FC $\geq 2$ ) and downregulated (Log2FC $\leq-2$ ) DEGs detected for Sporobolomyces sp. grown in the presence of $50 \mu \mathrm{g} / \mathrm{ml}$ of PAT at $\mathrm{OD}_{595}$ of $\sim 0.25$. BLASTx against existing Sporobolomyces sp. genome annotation and SGD is also shown. DEGs have been sorted from the highest Log2FC value to the smallest. In bold are indicated DEGs found also for Sporobolomyces sp. incubated in the presence of $5 \mu \mathrm{g} / \mathrm{ml}$ of PAT reported in Additional files 7 and 9. (XLSX $58 \mathrm{~kb}$ )

\section{Abbreviations}

ABC: ATP binding cassette; BCA: biocontrol agent; CPY: carboxypeptidase Y; DEGs: differentially expressed genes; DPA: desoxypatulinic acid; EC: European Commission; ER: endoplasmic reticulum; FDR: false discovery rate; FPKM: fragments per kilobase of exon per million fragments mapped; GMC: glucose-methanol-choline; GO: gene ontology; GSH: glutathione; GSSG: glutathione disulfide; $\mathrm{H}_{2} \mathrm{O}_{2}$ : hydrogen peroxide; HOG: high osmolarity glycerol; MFS: major facilitator superfamily; NGS: next generation sequence; OD: optical density; PAT: patulin; RABT: reference annotation based transcript; RNAseq: RNA sequencing; ROS: reactive oxygen species; SGD: Saccharomyces genome database; SRA: sequence read archive; UTRs: untranslated regions.

\section{Competing interests}

The authors declare that they have no competing interests.

\section{Authors' contributions}

$\mathrm{Gl}, \mathrm{Al}, \mathrm{RC}$ conceived the study and participated in its design and coordination. $\mathrm{Gl}$ carried out the experiments and the bioinformatics analyses. Gl, Al, RC wrote the manuscript. All authors read and approved the final manuscript.

\section{Acknowledgements}

We wish to thank William Spollen of the Informatics Research Core Facility of the University of Missouri-Columbia for technical assistance during the bioinformatics analyses. The computations were performed on the HPC resources at the University of Missouri Bioinformatics Consortium (UMBC). This research was supported by PRIN 2008 - prot. 2008JKH2MM "Exploitation of genes and proteins from different biological sources for limiting patulin contamination caused by the pathogenic fungus Penicillium expansum" (to RC), by a grant from the Dipartimento di Agricoltura, Ambiente e Alimenti (to GI), and by the University of Missouri Research Board and the U.S. National Institutes of Health (NIAID R21 Al094364) (to Al).

\section{Author details}

${ }^{1}$ Dipartimento di Agricoltura, Ambiente e Alimenti, Università degli Studi del Molise, Via F. De Sanctis snc, 86100 Campobasso, Italy. ${ }^{2}$ Division of Cell Biology and Biophysics, School of Biological Sciences, University of Missouri-Kansas City, Kansas City, MO 64110, USA. ${ }^{3}$ School of BioSciences, University of Melbourne, Melbourne, VIC 3010, Australia. ${ }^{4}$ Present address: Department of Molecular Genetics and Microbiology, Duke University Medical Center, Durham, NC 27710, USA.

\section{Received: 4 December 2015 Accepted: 28 February 2016}

Published online: 09 March 2016

\section{References}

1. Moake MM, Padilla-Zakour OI, Worobo RW. Comprehensive review of patulin control methods in foods. Compr Rev Food Sci Food Saf. 2005;1:8-21.

2. Puel O, Galtier P, Oswald IP. Biosynthesis and toxicological effects of patulin. Toxins (Basel). 2010:2(4):613-31.

3. Fliege R, Metzler M. The mycotoxin patulin induces intra- and intermolecular protein crosslinks in vitro involving cysteine, lysine, and histidine side chains, and alpha-amino groups. Chem Biol Interact. 1999;123(2):85-103.

4. Fliege R, Metzler M. Electrophilic properties of patulin. N-acetylcysteine and glutathione adducts. Chem Res Toxicol. 2000;13(5):373-81.

5. Barhoumi R, Burghardt RC. Kinetic analysis of the chronology of patulin- and gossypol-induced cytotoxicity in vitro. Fundam Appl Toxicol. 1996;30(2):290-7.

6. Liu BH, Wu TS, Yu FY, Su CC. Induction of oxidative stress response by the mycotoxin patulin in mammalian cells. Toxicol Sci. 2007:95(2):340-7.

7. Ferrer E, Juan-García A, Font G, Ruiz MJ. Reactive oxygen species induced by beauvericin, patulin and zearalenone in CHO-K1 cells. Toxicol In Vitro. 2009;23(8):1504-9.

8. Zhou SM, Jiang LP, Geng CY, Cao J, Zhong LF. Patulin-induced genotoxicity and modulation of glutathione in HepG2 cells. Toxicon. 2009;53(5):584-6.

9. Iwahashi $Y$, Hosoda H, Park JH, Lee JH, Suzuki Y, Kitagawa E, et al. Mechanisms of patulin toxicity under conditions that inhibit yeast growth J Agric Food Chem. 2006;54(5):1936-42.

10. Papp G, Horváth E, Mike N, Gazdag Z, Belágyi J, Gyöngyi Z, Bánfalvi G, Hornok L, Pesti M. Regulation of patulin-induced oxidative stress processes in the fission yeast Schizosaccharomyces pombe. Food Chem Toxicol. 2012;50(10):3792-8.

11. Breitenbach M, Weber M, Rinnerthaler M, Karl T, Breitenbach-Koller L. Oxidative stress in fungi: its function in signal transduction, interaction with plant hosts, and lignocellulose degradation. Biogeosciences. 2015;5(2):318-42.

12. Farrugia $G$, Balzan R. Oxidative stress and programmed cell death in yeast. Front Oncol. 2012;2:64

13. Paul S, Doering TL, Moye-Rowley WS. Cryptococcus neoformans Yap1 is required for normal fluconazole and oxidative stress resistance. Fungal Genet Biol. 2015;74:1-9.

14. Horváth E, Papp G, Belágyi J, Gazdag Z, Vágvölgyi C, Pesti M. In vivo direct patulin-induced fluidization of the plasma membrane of fission yeast Schizosaccharomyces pombe. Food Chem Toxicol. 2010;48(7):1898-904.

15. Horvath E, Nagy G, Turani M, Balogh E, Papp G, Pollak E, Pocsi I, Pesti M Banfalvi $G$. Effect of the fungal mycotoxin patulin on the chromatin 
structure of fission yeast Schizosaccharomyces pombe. J Basic Microbiol. 2012;52(6):642-52.

16. IARC. Patulin. Lyon, France: IARC; 1986. p. 83-98.

17. Glaser N, Stopper H. Patulin: Mechanism of genotoxicity. Food Chem Toxicol. 2012;50(5):1796-801.

18. WHO. World health organization, 44th report of the joint FAO/WHO expert committee on food additives. Technical report series, 859. Rome, Italy: WHO; 1995.

19. Harris KL, Bobe G, Bourquin LD. Patulin surveillance in apple cider and juice marketed in Michigan. J Food Prot. 2009;72(6):1255-61.

20. Ritieni A. Patulin in Italian commercial apple products. J Agric Food Chem. 2003;51(20):6086-90.

21. Morales H, Marín S, Ramos AJ, Sanchis V. Influence of post-harvest technologies applied during cold storage of apples in Penicillium expansum growth and patulin accumulation: A review. Food Control. 2010;21:953-62.

22. Tannous J, El Khoury R, Snini SP, Lippi Y, El Khoury A, Atoui A, Lteif R, Oswald IP, Puel O. Sequencing, physical organization and kinetic expression of the patulin biosynthetic gene cluster from Penicillium expansum. Int J Food Microbiol. 2014;189:51-60

23. Sanzani SM, Reverberi M, Punelli M, Ippolito A, Fanelli C. Study on the role of patulin on pathogenicity and virulence of Penicillium expansum. Int J Food Microbiol. 2012;153(3):323-31.

24. Ballester AR, Marcet-Houben M, Levin E, Sela N, Selma-Lázaro C, Carmona L, Wisniewski M, Droby S, González-Candelas L, Gabaldón T. Genome, transcriptome, and functional analyses of Penicillium expansum provide new insights into secondary metabolism and pathogenicity. Mol Plant Microbe Interact. 2015;28(3):232-48.

25. Li B, Zong Y, Du Z, Chen Y, Zhang Z, Qin G, Zhao W, Tian S. Genomic characterization reveals insights into patulin biosynthesis and pathogenicity in Penicillium species. Mol Plant Microbe Interact. 2015;28(6):635-47.

26. Snini SP, Tannous J, Heuillard P, Bailly S, Lippi Y, Zehraoui E, Barreau C, Oswald IP, Puel $\mathrm{O}$ : The patulin is a cultivar dependent aggressiveness factor favoring the colonization of apples by Penicillium expansum. Mol Plant Pathol. 2015. doi:10. 1111/mpp.12338. [Epub ahead of print].

27. Mahunu GK, Zhang H, Yang Q, Li C, Zheng X: Biological control of patulin by antagonistic yeast: A case study and possible model. Crit Rev Microbiol. 2015:1-13. [Epub ahead of print].

28. Castoria R, Morena V, Caputo L, Panfili G, De Curtis F, De Cicco V. Effect of the biocontrol yeast Rhodotorula glutinis strain LS11 on patulin accumulation in stored apples. Phytopathology. 2005;95(11):1271-8.

29. Castoria R, Mannina L, Durán-Patrón R, Maffei F, Sobolev AP, De Felice DV, et al. Conversion of the mycotoxin patulin to the less toxic desoxypatulinic acid by the biocontrol yeast Rhodosporidium kratochvilovae strain LS11. J Agric Food Chem. 2011;59(21):11571-8.

30. laniri G, Idnurm A, Wright SA, Durán-Patrón R, Mannina L, Ferracane R, Ritieni A, Castoria R. Searching for genes responsible for patulin degradation in a biocontrol yeast provides insight into the basis for resistance to this mycotoxin. Appl Environ Microbiol. 2013;79(9):3101-15

31. Zhu R, Feussner K, Wu T, Yan F, Karlovsky P, Zheng X. Detoxification of mycotoxin patulin by the yeast Rhodosporidium paludigenum. Food Chem. 2015;179:1-5.

32. Moss MO, Long MT. Fate of patulin in the presence of the yeast Saccharomyces cerevisiae. Food Addit Contam. 2002:19(4):387-99.

33. Ricelli A, Baruzzi F, Solfrizzo M, Morea M, Fanizzi FP. Biotransformation of patulin by Gluconobacter oxydans. Appl Environ Microbiol. 2007;73(3):785-92

34. Sumaiya H, William V, Sahar K, Ali BK, Richard B, Jane B. Biotransformation of patulin to hydroascladiol by Lactobacillus plantarum. Food Control. 2013;34(2):502-8.

35. Suzuki T, Iwahashi Y. Gene expression profiles of yeast Saccharomyces cerevisiae sod 1 caused by patulin toxicity and evaluation of recovery potential of ascorbic acid. J Agric Food Chem. 2011;59(13):7145-54.

36. Duplessis S, Cuomo CA, Lin YC, Aerts A, Tisserant E, Veneault-Fourrey C, et al. Obligate biotrophy features unraveled by the genomic analysis of rust fungi. Proc Natl Acad Sci U S A. 2011;108(22):9166-71.

37. laniri $G$, Abhyankar R, Kihara A, Idnurm A. Phs1 and the synthesis of very long chain fatty acids are required for ballistospore formation. PLoS One. 2014;9(8):e105147.

38. Trapnell C, Roberts A, Goff L, Pertea G, Kim D, Kelley DR, Pimentel H, Salzberg SL, Rinn JL, Pachter L. Differential gene and transcript expression analysis of RNA-seq experiments with TopHat and Cufflinks. Nat Protoc. 2012;7(3):562-78.
39. Janbon G, Ormerod KL, Paulet D, Byrnes EJ, Yadav V, Chatterjee G, Mullapudi N, Hon CC, Billmyre RB, Brunel F et al. Analysis of the genome and transcriptome of Cryptococcus neoformans var. grubii reveals complex RNA expression and microevolution leading to virulence attenuation. PLoS Genet. 2014;10(4):e1004261.

40. Ricarte F, Menjivar R, Chhun S, Soreta T, Oliveira L, Hsueh T, Serranilla M, Gharakhanian E. A genome-wide immunodetection screen in S. cerevisiae uncovers novel genes involved in lysosomal vacuole function and morphology. PLoS One. 2011;6(8):e23696.

41. Garay-Arroyo A, Covarrubias AA. Three genes whose expression is induced by stress in Saccharomyces cerevisiae. Yeast. 1999;15(10A):879-92.

42. Tkach JM, Yimit A, Lee AY, Riffle M, Costanzo M, Jaschob D, Hendry JA, Ou J, Moffat J, Boone C et al. Dissecting DNA damage response pathways by analysing protein localization and abundance changes during DNA replication stress. Nat Cell Biol. 2012;14(9):966-76

43. Rai R, Tate JJ, Cooper TG. Ure2, a prion precursor with homology to glutathione S-transferase, protects Saccharomyces cerevisiae cells from heavy metal ion and oxidant toxicity. J Biol Chem. 2003;278(15):12826-33.

44. Rai R, Cooper TG. In vivo specificity of Ure2 protection from heavy metal ion and oxidative cellular damage in Saccharomyces cerevisiae. Yeast. 2005:22(5):343-58.

45. Coschigano PW, Magasanik B. The URE2 gene product of Saccharomyces cerevisiae plays an important role in the cellular response to the nitrogen source and has homology to glutathione S-transferases. Mol Cell Biol. 1991;11(2):822-32

46. Dias PJ, Seret ML, Goffeau A, Correia IS, Baret PV. Evolution of the 12-spanner drug:H+ antiporter DHA1 family in hemiascomycetous yeasts. OMICS. 2010;14(6):701-10.

47. Krüger A, Vowinckel J, Mülleder M, Grote P, Capuano F, Bluemlein K, Ralser M. Tpo1-mediated spermine and spermidine export controls cell cycle delay and times antioxidant protein expression during the oxidative stress response. EMBO Rep. 2013;14(12):1113-9.

48. Morgan B, Ezerina D, Amoako TN, Riemer J, Seedorf M, Dick TP. Multiple glutathione disulfide removal pathways mediate cytosolic redox homeostasis. Nat Chem Biol. 2013;9(2):119-25.

49. Sasser TL, Lawrence G, Karunakaran S, Brown C, Fratti RA. The yeast ATP-binding cassette (ABC) transporter Ycf1 $p$ enhances the recruitment of the soluble SNARE Vam7p to vacuoles for efficient membrane fusion. J Biol Chem. 2013;288(25):18300-10.

50. Sumbu ZL, Thonart P, Bechet J. Action of patulin on a yeast. Appl Environ Microbiol. 1983;45(1):110-5.

51. Taylor JW, Berbee ML. Dating divergences in the fungal tree of life: review and new analyses. Mycologia. 2006;98:838-49.

52. Fliege $R$, Metzler M. Electrophilic properties of patulin. Adduct structures and reaction pathways with 4-bromothiophenol and other model nucleophiles. Chem Res Toxicol. 2000;13(5):363-72.

53. Riley RT, Showker JL. The mechanism of patulin's cytotoxicity and the antioxidant activity of indole tetramic acids. Toxicol Appl Pharmacol. 1991;109(1):108-26.

54. Upadhya R, Campbell LT, Donlin MJ, Aurora R, Lodge JK. Global transcriptome profile of Cryptococcus neoformans during exposure to hydrogen peroxide induced oxidative stress. PLoS One. 2013:8(1):e55110.

55. Donmez-Altuntas H, Gokalp-Yildiz P, Bitgen N, Hamurcu Z. Evaluation of genotoxicity, cytotoxicity and cytostasis in human lymphocytes exposed to patulin by using the cytokinesis-block micronucleus cytome (CBMN cyt) assay. Mycotoxin Res. 2013;29(2):63-70.

56. Liu BH, Yu FY, Wu TS, Li SY, Su MC, Wang MC, Shih SM. Evaluation of genotoxic risk and oxidative DNA damage in mammalian cells exposed to mycotoxins, patulin and citrinin. Toxicol Appl Pharmacol. 2003;191(3):255-63.

57. Upadhya R, Kim H, Jung KW, Park G, Lam W, Lodge JK, Bahn YS. Sulphiredoxin plays peroxiredoxin-dependent and -independent roles via the HOG signalling pathway in Cryptococcus neoformans and contributes to fungal virulence. Mol Microbiol. 2013;90(3):630-48.

58. Gueldry O, Lazard M, Delort F, Dauplais M, Grigoras I, Blanquet S, Plateau P. Ycf1p-dependent $\mathrm{Hg}(\mathrm{II})$ detoxification in Saccharomyces cerevisiae. Eur J Biochem. 2003;270(11):2486-96.

59. Li ZS, Szczypka M, Lu YP, Thiele DJ, Rea PA. The yeast cadmium factor protein (YCF1) is a vacuolar glutathione S-conjugate pump. J Biol Chem. 1996;271(11):6509-17. 
60. Li ZS, Lu YP, Zhen RG, Szczypka M, Thiele DJ, Rea PA. A new pathway for vacuolar cadmium sequestration in Saccharomyces cerevisiae: YCF1-catalyzed transport of bis(glutathionato)cadmium. Proc Natl Acad Sci U S A. 1997:94(1):42-7.

61. Takahashi-Ando N, Kimura M, Kakeya H, Osada H, Yamaguchi I. A novel lactonohydrolase responsible for the detoxification of zearalenone: enzyme purification and gene cloning. Biochem J. 2002;365(Pt 1):1-6.

62. Sekiguchi J, Shimamoto T, Yamada Y, Gaucher GM. Patulin biosynthesis: enzymatic and nonenzymatic transformations of the mycotoxin (E)-ascladiol. Appl Environ Microbiol. 1983;45(6):1939-42.

63. Dos Santos SC, Teixeira MC, Cabrito TR, Sá-Correia I. Yeast toxicogenomics: genome-wide responses to chemical stresses with impact in environmental health, pharmacology, and biotechnology. Front Genet. 2012;3:63.

64. Lilly VG, Barnett HL. Physiology of the Fungi. New York: McGraw-Hill; 1951.

65. Conesa A, Götz S, García-Gómez JM, Terol J, Talón M, Robles M. Blast2GO: a universal tool for annotation, visualization and analysis in functional genomics research. Bioinformatics. 2005;21(18):3674-6.

Submit your next manuscript to BioMed Central and we will help you at every step:

- We accept pre-submission inquiries

- Our selector tool helps you to find the most relevant journal

- We provide round the clock customer support

- Convenient online submission

- Thorough peer review

- Inclusion in PubMed and all major indexing services

- Maximum visibility for your research

Submit your manuscript at www.biomedcentral.com/submit
Biomed Central 